\title{
The Scope of Pharmacognosy Today \& Tomorrow
}

\section{Taviad $\mathrm{K}^{1 *}$ and Vekariya $\mathrm{S}^{2}$}

1Department of Rasa Shastra and Bhaishajya Kalpana, Gujarat Ayurved University, India

2Department of Dravyaguna, Gujarat Ayurved University, India

\section{Editorial}

Volume 2 Issue 1

Received Date: February 02, 2018

Published Date: February 08, 2018

*Corresponding author: Krushnkumar Taviad, PhD Scholar, Department of Rasa Shastra and Bhaishajya Kalpana, Institute for Post Graduate Teaching and Research in Ayurveda, Gujarat Ayurved University, Gujarat, India, E-mail: drkrishnat@gmail.com

\section{Editorial}

Pharmacognosy, derived from the Greek words "pharmakon" (drug) and "gnosis" (knowledge), is the study of medicinal drugs derived from plants or other natural sources [1]. Healing with medicinal plants is as old as mankind itself. Herbal medicines as the major remedy in ancient system of medicine are employed in medical practices since antiquity. The documents many of which are of great antiquity, unconcealed that plants were used medicinally in India, china, Egypt and Greece long before the beginning of the Common Era [2]. The Indian holy books Vedas mention treatment with plants, which are abundant in that country. Numerous spice plants used even today originate from India: nutmeg, pepper, clove, etc [3]. The American Society of Pharmacognosy defines pharmacognosy as "the study of the physical, chemical, biochemical and biological properties of drugs, drug substances or potential drugs or drug substances of natural origin as well as the search for new drugs from natural sources" [4]. Modern Pharmacognosy involves the broad study of natural products from various sources including plants, bacteria, fungi, and marine organisms [5]. Plant preparations are said to be medicinal or herbal when they are used to promote health beyond basic nutrition. This study acts as an important link between pharmacology and medicinal chemistry which also plays a vital role between Ayurvedic and allopathic systems of medicines. Botany includes the identification (taxonomy), genetics, and cultivation of plants. Chemical characterization of includes the isolation, identification and quantification of constituents in plant materials. The pharmacognosy is a rapidly developing science which deals with the complete and systemic knowledge of crude drugs which will be useful to mankind in order to relieve diseases in human beings and as well as it helps for the manufacturers or in pharmacies.

\section{Field of Pharmacognosy}

a) The study of the medicinal properties of natural products, for the purposes of drug discovery and understanding how dietary supplements work.

b) The development and use of analytical methods for quality control of natural products in the marketplace.

c) The study of the use of traditional remedies by native cultures.

d) The microscopic evaluation and species verification of medicinal or economically important natural products.

e) The use of natural products for specific agricultural purposes, such as natural pesticides or insect antifeedants.

f) The study of the safety and functional properties of compounds found in novel foods or food ingredients and consumer products.

g) The cosmetic application of natural compounds or extracts.

h) The study and manipulation of genetic biosynthetic pathways for the purpose of enhancing the production of natural compounds, or producing novel compounds [6].

\section{Scope of Pharmacognosy}

Natural medicines have been used to enhance human and veterinary health since time immemorial and the success of modern medical science largely depends on drugs originally obtained from natural resources. In the 
past, traditional medicinal knowledge prevalent in the form of holy books, incantations, folklores, Materia Medica and other historical literature defined the preliminary guidelines for the authorization of plant derived natural medicines [7]. The conventional medical practices adopted for identification and authentication of natural remedies eventually framed the botanico-chemical approach to Pharmacognosy during the early $19^{\text {th }}$ century. However, the last 200 years witnessed a substantial metamorphosis in the principles and practices of Pharmacognosy and it has become an essential domain of modern pharmaceutical science as a multidisciplinary high-tech science of natural medicines. In a contemporary context, the systematic study of natural medicines in terms of purity, potency, consistency and safety have become the major issues in Pharmacognosy [1]. Moreover, most of the present day's drug discoveries have been increasingly adopting traditional medicine based approaches to increase results and to address safety concerns. Thus, Clinical Pharmacognosy, Analytical Pharmacognosy and Industrial Pharmacognosy have been established as the specialized and professional offshoots of Pharmacognosy to meet the contemporary advancements in the field of Pharmacognosy. Furthermore, Molecular Pharmacognosy, Genomic Pharmacognosy and Metabolomic Pharmacognosy have been deemed as the promising approaches of Pharmacognosy research to accommodate future demands in molecular biology, biotechnology and analytical chemistry of natural medicines plus medicinal plants. Nevertheless, interdisciplinary collaborative research programmes are essential for integrated development of traditional medicines and Pharmacognosy research and education.

International Journal of Pharmacognosy \& Chinese Medicine (IPCM) is a new journal published by MedWin Publishers (International Standard Serial Number ISSN: 2576-4772). We aim to publish high quality original research articles, critical reviews, clinical perspectives, opinions, short communications, case reports, news, proceedings, health policies etc., of all aspects of pharmacognosy research. The journal is aimed at a broad readership, publishing articles on all aspects of pharmacognosy and related fields. The scope of the journal is to provide an international opportunity for encouraging noble discussions and thus contributing the best understanding the use of natural products and \& their effects for curing many diseases naturally and benefiting the readers, authors by accelerating the dissemination of research information providing maximum access towards current academic and clinical information on current topic. The submissions of original contributions in all areas of Pharmacognosy are welcomed.

\section{References}

1. (2007) The American Heritage Medical Dictionary, Houghton Mifflin Company, USA.

2. Divya A (2015) Pharmacognosy: Facts and Future. Research \& Reviews: Journal of Pharmacognosy and Phytochemistry 3(2): 1-8.

3. Bijendra Bauer Pertovska (2012) Historical review of medicinal plants' usage. Pharmacogn Rev 6(11): 1-5.

4. https://en.wikipedia.org/wiki/Pharmacognosy

5. Satyajit D Sarker (2012) Pharmacognosy in modern pharmacy curricula. Pharmacogn Mag 8(30): 91-92.

6. (2007) The American Heritage Medical Dictionary, Houghton Mifflin Company, USA.

7. Namraj Dhami (2013) Trends in Pharmacognosy: A modern science of natural medicines. Journal of Herbal Medicine 3(4): 123-131. 